\title{
A Phosphorylation-Induced Switch in the Nuclear Localization Sequence of the Intrinsically Disordered NUPR1 Hampers Binding to Importin
}

\author{
José L. Neira ${ }^{1,2, *(\mathcal{C}}$, Bruno Rizzuti ${ }^{3}{ }^{\circledR}$, Ana Jiménez-Alesanco ${ }^{2}$, Martina Palomino-Schätzlein ${ }^{4}\left({ }^{\circ}\right.$, \\ Olga Abián ${ }^{2,5,6,7,8}$ ) Adrián Velázquez-Campoy $2,5,6,7,9 \oplus$ and Juan L. Iovanna ${ }^{10, *(1)}$ \\ 1 Instituto de Biología Molecular y Celular, Universidad Miguel Hernández, 03202 Elche, Spain \\ 2 Instituto de Biocomputación y Física de Sistemas Complejos (BIFI), Joint Units IQFR-CSIC-BIFI, \\ and GBsC-CSIC-BIFI, Universidad de Zaragoza, 50009 Zaragoza, Spain; ajimenez@bifi.es (A.J.-A.); \\ oabifra@unizar.es (O.A.); adrianvc@unizar.es (A.V.-C.) \\ 3 CNR-NANOTEC, Licryl-UOS Cosenza and CEMIF.Cal, Department of Physics, University of Calabria, \\ Via P. Bucci, Cubo 31 C, 87036 Arcavacata di Rende, Cosenza, Italy; bruno.rizzuti@cnr.it \\ 4 Centro de Investigación Príncipe Felipe, 41930 Valencia, Spain; martina@tinet.org \\ 5 Instituto de Investigación Sanitaria Aragón (IIS Aragón), 50009 Zaragoza, Spain \\ 6 Centro de Investigación Biomédica en Red en el Área Temática de Enfermedades Hepáticas y \\ Digestivas (CIBERehd), 28029 Madrid, Spain \\ 7 Departamento de Bioquímica y Biología Molecular y Celular, Universidad de Zaragoza, \\ 50009 Zaragoza, Spain \\ 8 Instituto Aragonés de Ciencias de la Salud (IACS), 50009 Zaragoza, Spain \\ 9 Fundación ARAID, Gobierno de Aragón, 50009 Zaragoza, Spain \\ 10 Centre de Recherche en Cancérologie de Marseille (CRCM), INSERM U1068, CNRS UMR 7258, \\ Aix-Marseille Université and Institut Paoli-Calmettes, Parc Scientifique et Technologique de Luminy, \\ 163 Avenue de Luminy, 13288 Marseille, France \\ * Correspondence: jlneira@umh.es (J.L.N.); juan.iovanna@inserm.fr (J.L.I.); \\ Tel.: +34-96-6658475 (J.L.N.); +33-(0)4-9182-8803 (J.L.I.)
}

Received: 23 August 2020; Accepted: 9 September 2020; Published: 11 September 2020

check for updates

\begin{abstract}
Several carrier proteins are involved in protein transport from the cytoplasm to the nucleus in eukaryotic cells. One of those is importin $\alpha$, of which there are several human isoforms; among them, importin $\alpha 3$ (Imp $\alpha 3)$ has a high flexibility. The protein NUPR1, a nuclear protein involved in the cell-stress response and cell cycle regulation, is an intrinsically disordered protein (IDP) that has a nuclear localization sequence (NLS) to allow for nuclear translocation. NUPR1 does localize through the whole cell. In this work, we studied the affinity of the isolated wild-type NLS region (residues 54-74) of NUPR1 towards Imp $\alpha 3$ and several mutants of the NLS region by using several biophysical techniques and molecular docking approaches. The NLS region of NUPR1 interacted with Imp $\alpha 3$, opening the way to model the nuclear translocation of disordered proteins. All the isolated NLS peptides were disordered. They bound to Imp $\alpha 3$ with low micromolar affinity $(1.7-27 \mu \mathrm{M})$. Binding was hampered by removal of either Lys65 or Lys69 residues, indicating that positive charges were important; furthermore, binding decreased when Thr68 was phosphorylated. The peptide phosphorylated at Thr68, as well as four phospho-mimetic peptides (all containing the Thr68Glu mutation), showed the presence of a sequential NN $(i, i+1)$ nuclear Overhauser effect (NOE) in the $2 \mathrm{D}-{ }^{1} \mathrm{H}-\mathrm{NMR}$ (two-dimensional-proton NMR) spectra, indicating the presence of turn-like conformations. Thus, the phosphorylation of Thr68 modulates the binding of NUPR1 to Imp $\alpha 3$ by a conformational, entropy-driven switch from a random-coil conformation to a turn-like structure.
\end{abstract}


Keywords: circular dichroism; flexibility; fluorescence; importin; intrinsically disordered protein; isothermal titration calorimetry (ITC); molecular docking; nuclear magnetic resonance (NMR); nuclear protein 1 (NPR1); peptide

\section{Introduction}

Active nuclear translocation happens through importins (also known as karyopherins), together with other proteins such as the GTPase Ran and nucleoporins [1-3]. The classical nuclear import pathway is started by recognition of a nuclear localization sequence (NLS) in the cargo by importin $\alpha$ [4]. The complex cargo importin $\alpha$ binds to importin $\beta$; then, this complex goes through the nuclear pore complex (NPC). The GTPase Ran dissociates the ternary complex within the nucleus by interacting with importin $\beta$, and both importins $\alpha$ and $\beta$ are recycled back to the cytoplasm [4]. The human genome encodes seven isoforms of importin $\alpha$, with three subtypes [4-6]. These isoforms have a role in cell differentiation, gene regulation [5,7], and even in viral infections, because some viral proteins are recognized by specific importins [8].

Importin $\alpha$ is a modular protein built of $\alpha$-helix repeat armadillo (ARM) units [1,4]. It has two domains: (i) a N-terminal importin $\beta$-binding (IBB) domain, approximately 60-residues-long, which is used for binding to importin $\beta$ before transport through the NPC, and (ii) a C-terminal NLS-binding motif formed by ten ARM units [9]. Structures of several truncated importin $\alpha$, without the IBB domain [8,9], have shown that the cargo NLS region binds in a disordered conformation. This interaction occurs at a concave site of the elongated structure, involving ARM motifs 2 to 4 (major site) or 6 to 8 (minor site) for the shortest classical monopartite NLSs or both sets of ARM motifs for the largest bipartite NLS regions. When importin $\beta$ is not present, the IBB domain, which mimics an NLS region, occupies the ARM motifs involved in NLS recognition [9]. This intramolecular interaction has an autoinhibitory role, and it is thought to be relevant in cargo dissociation in the nucleoplasmic side [9].

Intrinsically disordered proteins (IDPs) do not have a unique stable conformation, resulting in a dynamic conformational ensemble that is reflected in a high structural flexibility. They are involved in cell cycle control, signaling, molecular recognition, replication, and transcription processes [10-13]. The discovery of IDPs has shown that protein biological activity is possible even without a well-defined structure [12-14] but, rather, with an extreme structural flexibility. However, IDPs may have a propensity to adopt structures at the local level; this acquisition of local order can be achieved by, among other factors, post-translational modifications [14]. Such modifications, in turn, can widen their biological functions [11,15]. NUPR1 (UniProtKB O60356) is an 82-residue-long (8 kDa), highly basic, monomeric IDP that is overexpressed during the acute phase of pancreatitis [16,17] and in almost any, if not all, cancer tissues [18]. Its exact functions are unknown, but NUPR1 is a key element in the cell-stress response and cell-cycle regulation [18,19]. Moreover, NUPR1 intervenes in apoptosis through the formation of a complex with the oncoprotein ProT $\alpha$ [20] and in DNA repair [21,22]. In the interactions with all these partners and other synthetic molecules, NUPR1 uses two hotspots around residues Ala33 and Thr68 [22-24]. In addition, NUPR1 has a bipartite NLS region around Thr68, which is fully functional [25]. Thus, even though NUPR1 is a relatively small protein, it might require the assistance of the importin system for nuclear translocation due to its unfolded nature and its large radius of gyration, which would be closer to the limit of free diffusion through the NPC. In addition, NUPR1 might require the presence of importins to avoid undesired interactions with other macromolecules in the cytoplasm, due to its basic nature [26].

In this work, we have studied the interaction of human importin $\alpha 3$ (Imp $\alpha 3$ ), also called KPNA4, and that of its truncated species, without the IBB domain $(\Delta \operatorname{Imp} \alpha 3)$, to either NUPR1 or peptides encompassing its NLS (NLS-NUPR1). We have chosen Imp $\alpha 3$ as a target for NUPR1 because of its larger flexibility when compared with other importins, as concluded by the structural factors 
from the X-ray data, which confers in it a greater ability to interact with cargos, having a higher variety of conformations [8]. From an experimental pint of view, Imp $\alpha 3$ can be also easily expressed and purified for in vitro structural studies [8]. Interestingly, it has also been shown to be crucial in pain pathways [27]. In addition, by studying both importin species (with and without the IBB), we were interested in finding out whether the absence of the IBB domain affected the binding of NLS-NUPR1. The NLS-NUPR1 peptides had mutations at: (i) the two lysines in the sequence (Lys65 and Lys69), which are important for nuclear translocation, according to in vivo studies [25], and (ii) Thr68, where we have either introduced phospho-threonine or, alternatively, we have designed phospho-mimetic mutations (with a glutamic residue). We have used several spectroscopic and biophysical techniques-namely, steady-state fluorescence, circular dichroism (CD), nuclear magnetic resonance (NMR), isothermal titration calorimetry (ITC), and molecular docking-to address the binding of the peptides to both importins. Our results indicate that the isolated wild-type (wt) NLS-NUPR1, as well as the mutants, were monomeric and disordered in the solution. The wt NLS-NUPR1 peptide bound to both importins, and the affinity was larger for $\Delta \operatorname{Imp} \alpha 3(0.95 \mu \mathrm{M}$ versus $1.7 \mu \mathrm{M}$ for Imp $\alpha 3$ ), indicating that the IBB region must have an inhibitory effect; this result is in agreement with other binding studies involving intact, well-folded protein cargos [9], but to the best of our knowledge, this is the first time tested with an IDP. The binding of NLS-NUPR1 peptides to both importins was hampered by removal of either Lys65 or Lys69, and it was almost abolished when Thr68 was phosphorylated or when the phospho-mimetics were assayed. Interestingly enough, the phosphorylated peptide at Thr68 and the four phospho-mimetics showed the presence of turn-like conformations, which were not observed in the wt NLS-NUPR1 peptide or in the Lys65Ala or Lys69Ala mutants. We concluded that the phosphorylation of Thr68 modulates the binding of NUPR1 to importin by a conformational switch from a random-coil to a turn-like conformation.

\section{Materials and Methods}

\subsection{Materials}

Isopropyl- $\beta$-D-1-tiogalactopyranoside and ampicillin were obtained from Apollo Scientific (Stockport, UK). Imidazole, kanamycin, Trizma base, and His-Select HF nickel resin were from Sigma-Aldrich (Madrid, Spain). Protein marker (PAGEmark Tricolor) and Triton X-100 were from VWR (Barcelona, Spain). Amicon centrifugal devices were from Millipore (Barcelona, Spain), and they had a cut-off molecular weight of 30 or $50 \mathrm{kDa}$. The rest of the materials were of analytical grade. Water was deionized and purified on a Millipore system.

\subsection{Protein Expression and Purification}

The His-tagged $\Delta \operatorname{Imp} \alpha 3$ (residues 64-521) was obtained from BL21 (DE3) cells as described [8]. The DNA of the codon-optimized, intact Imp $\alpha 3$ with a His-tag at the $\mathrm{N}$ terminus was synthesized by NZYtech (Lisbon, Portugal) and cloned into the pHTP1 vector (with kanamycin resistance). Expression and purification of $\operatorname{Imp} \alpha 3$ were carried out as those for $\Delta \operatorname{Imp} \alpha 3$ in the same Escherichia coli strain. Concentration of both species was determined from their six tyrosines and six tryptophans [28].

\subsection{Design and Synthesis of the Peptides}

The peptides were synthesized by NZYtech with a purity of $95 \%$. The peptides comprised the NLS region of NUPR1 (Table 1); peptides were named with the accompanying name within parenthesis for each sequence, as reported in Table 1 . All peptides were acetylated and amidated at the $\mathrm{N}$ and $\mathrm{C}$ termini, respectively, to avoid fraying effects. As the wt NLS had no tyrosine, we introduced one at the $\mathrm{N}$ terminus to allow for absorbance measurements [28]. We synthesized eight peptides with different mutations, with the following rationale: (i) we studied the importance of positions Lys65 and Lys69 in the binding to both importins by mutating the two positions to alanine, (ii) we mutated Thr68 to the glutamic T68E peptide to have a phosphomimic at this position, (iii) we combined this mutation at 
Thr68 with either of the other two as double mutants, as well as to both in a triple mutant, and (iv) we designed the phosphorylated peptide at position Thr68 (pT68 peptide) to study the effects of this single post-translational modification.

Table 1. Hydrodynamic properties of the nuclear localization sequence (NLS) NUPR1 peptides.

\begin{tabular}{|c|c|c|}
\hline Peptide $^{\text {a }}$ & $D\left(\mathrm{~cm}^{2} \mathrm{~s}^{-1}\right) \times 10^{6}\left(R_{\mathrm{h}}, \AA\right)^{\mathrm{b}}$ & $R_{\mathrm{h}}, \AA^{\mathrm{c}}$ \\
\hline YT $^{54}$ NRPSPGGHERKLVTKLQNSE (wt) & $1.85 \pm 0.04(11 \pm 1)$ & $13 \pm 3$ \\
\hline YTNRPSPGGHERALVTKLQNSE (K65A) & $1.94 \pm 0.08(11 \pm 1)$ & $13 \pm 3$ \\
\hline YTNRPSPGGHERKLVTALQNSE (K69A) & $1.79 \pm 0.06(12 \pm 2)$ & $13 \pm 3$ \\
\hline YTNRPSPGGHERKLVEKLQNSE (T68E) & $2.17 \pm 0.06(10 \pm 1)$ & $13 \pm 3$ \\
\hline YTNRPSPGGHERALVEKLQNSE (K65AT68E) & $1.76 \pm 0.06(12 \pm 1)$ & $13 \pm 3$ \\
\hline YTNRPSPGGHERKLVEALQNSE (T68EK69A) & $1.87 \pm 0.08(11 \pm 1)$ & $13 \pm 3$ \\
\hline YTNRPSPGGHERALVEALQNSE (K65AT68EK69A) & $2.4 \pm 0.2(9 \pm 2)$ & $13 \pm 3$ \\
\hline YTNRPSPGGHERKLVpTKLQNSE (pT68) & $1.89 \pm 0.08(11 \pm 1)$ & $13 \pm 3$ \\
\hline
\end{tabular}

a Mutations with respect to the wild-type sequence are indicated in bold. The last peptide has a phospho-threonine at position 68 (indicated with a " $\mathrm{pT}^{\prime \prime}$ ). ${ }^{\mathrm{b}}$ The $R_{\mathrm{h}}$ was determined from the translational diffusion coefficient of dioxane $\left(R_{\mathrm{h}}=2.12 \AA\right)$ added to each sample. ${ }^{\mathrm{c}}$ Calculated from the scale law: $R_{\mathrm{h}}=(0.027 \pm 0.01) \mathrm{MW}^{(0.50 \pm 0.01)}[29]$, where MW is the molecular weight of the peptide. $D$ : translational diffusion coefficient.

\subsection{Fluorescence}

\subsubsection{Steady-State Fluorescence}

Fluorescence spectra were collected on a Cary Varian spectrofluorometer (Agilent, Santa Clara, CA, USA) with a Peltier unit. The samples were prepared the day before and left overnight at $278 \mathrm{~K}$; before experiments, samples were left for $1 \mathrm{~h}$ at $298 \mathrm{~K}$. A 1-cm-pathlength quartz cell (Hellma, Kruibeke, Belgium) was used. Concentrations of the peptides were $10 \mu \mathrm{M}$ and that of importins was $4 \mu \mathrm{M}$. Samples containing the isolated peptide, the isolated importin, and the mixture of both, at those concentrations, were prepared for each peptide and each importin. Experiments were acquired at pH 7.0 in 50-mM phosphate buffer.

Protein samples were excited at 280 and $295 \mathrm{~nm}$ (although the samples of the isolated peptides did not show any fluorescence at the latter value). The other experimental parameters and the buffers used have been described elsewhere [30]. Appropriate blank corrections were made in all spectra.

\subsubsection{Thermal Denaturations}

Thermal denaturations were performed at $60 \mathrm{~K} / \mathrm{h}$ with an average time of $1 \mathrm{~s}$ for all samples. Thermal scans were collected at 315, 330, and $350 \mathrm{~nm}$ after excitation at 280 or $295 \mathrm{~nm}$ from 298 to $358 \mathrm{~K}$. The rest of the experimental set-up was the same as described above. Thermal denaturations for both importins were irreversible, as well as that of the complexes with any peptide. The apparent thermal denaturation midpoint was estimated from a two-state equilibrium equation as described [30].

\section{5. $C D$}

Far-ultraviolet (UV) CD spectra were collected on a Jasco J810 spectropolarimeter (Jasco, Tokyo, Japan) with a thermostated cell holder and interfaced with a Peltier unit at $298 \mathrm{~K}$. The instrument was periodically calibrated with (+)-10-camphorsulphonic acid. A path length cell of $0.1 \mathrm{~cm}$ was used (Hellma, Kruibeke, Belgium). All spectra were corrected by subtracting the corresponding baseline. The concentration of each polypeptide was the same used in the fluorescence experiments. The buffer was the same used in the fluorescence experiments.

\subsubsection{Far-Ultraviolet (UV) Spectra}

Isothermal wavelength spectra of each sample were acquired with six scans at a scan speed of $50 \mathrm{~nm} / \mathrm{min}$, with a response time of $2 \mathrm{~s}$ and a bandwidth of $1 \mathrm{~nm}$. The samples were prepared the 
day before and left overnight at $278 \mathrm{~K}$ to allow for equilibration. Before starting the experiments, the samples were further left for $1 \mathrm{~h}$ at $298 \mathrm{~K}$.

\subsubsection{Thermal Denaturations}

The experiments were performed at $60 \mathrm{~K} / \mathrm{h}$ and a response time of $8 \mathrm{~s}$. Thermal scans were collected by following the changes in ellipticity at $222 \mathrm{~nm}$ from 298 to $343 \mathrm{~K}$. The rest of the experimental set-up was the same as reported in the steady-state experiments. Thermal denaturations were not reversible for any of the samples, as shown by: (i) comparison of the spectra before and after the heating and (ii) changes in the voltage of the instrument detector [31]. The apparent thermal denaturation midpoint of the samples was estimated as described [30].

\subsection{ITC}

The experimental set-up and data processing of ITC experiments has been described previously [32]. Calorimetric titrations, performed in an Auto-iTC200 calorimeter (MicroCal, Malvern-Panalytical, Malvern, UK) consisted of series of $192-\mu \mathrm{L}$ injections, with $150 \mathrm{~s}$ time spacing and a 750-rpm stirring speed. Imp $\alpha 3$ or $\Delta \operatorname{Imp} \alpha 3($ at $10-20 \mu \mathrm{M})$ was loaded into the calorimetric cell and NLS-NUPR1 peptides in the syringe (150-300 $\mu \mathrm{M})$; all solutions were prepared in buffer Tris $50 \mathrm{mM}, \mathrm{pH}$ 8. The temperature for all the experiments was $298 \mathrm{~K}$. The experiments were analyzed by applying a model considering a single ligand binding site (1:1 stoichiometry) implemented in Origin 7.0 (OriginLab, Northampton, MA, USA). The binding affinity (association constant) and the binding enthalpy were estimated through a least-squares nonlinear regression data analysis, from which the Gibbs energy and the entropic contribution to the binding were calculated using well-known thermodynamic relationships. Since the binding stoichiometry is constrained by the model, the parameter $\mathrm{n}$ provides a fraction of the active or binding competent protein. Experiments for each peptide and importin species were performed, at least, in duplicates.

\section{7. $N M R$}

The NMR experiments were acquired at $283 \mathrm{~K}$ on a Bruker $500 \mathrm{MHz}$ Advance III spectrometer (Bruker $\mathrm{GmbH}$, Karlsruhe, Germany) equipped with a triple-resonance probe and z-pulse field gradients. Temperature of the probe was calibrated with methanol [33]. All experiments were carried out at $\mathrm{pH} 7.2,50-\mathrm{mM}$ deuterated Tris buffer (not corrected for isotope effects). The spectra were calibrated with TSP ((trimethylsilyl)-2,2,3,3-tetradeuteropropionic acid) by considering $\mathrm{pH}$-dependent changes of its chemical shifts [33].

\subsection{1. $1 \mathrm{D}-{ }^{1} \mathrm{H}-\mathrm{NMR}$ (One-Dimensional Proton NMR) Spectra}

In all cases, 128 scans were acquired with $16 \mathrm{~K}$ acquisition points and using concentrations of 1.0-1.2 mM. Homonuclear 1D- ${ }^{1} \mathrm{H}-\mathrm{NMR}$ spectra were processed with Bruker TopSpin 3.1 (Bruker $\mathrm{GmbH}$, Karlsruhe, Germany) after zero-filling and apodization with an exponential window.

\subsubsection{Translational NMR Diffusion Ordered Spectroscopy (DOSY)}

Concentrations of peptides in all DOSY experiments were $120 \mu \mathrm{M}$, and 128 scans, where the gradient strength was varied, were acquired for each curve. Translational self-diffusion measurements were performed with the pulsed gradient spin-echo sequence in the presence of $100 \% \mathrm{D}_{2} \mathrm{O}$. Experimental details have been described elsewhere [30]. Briefly, the gradient strength was varied in sixteen linear steps between $2 \%$ and $95 \%$ of the total power of the gradient coil. The gradient strength was previously calibrated by using the value of the translational diffusion coefficient, $D$, for the residual proton water line in a sample containing $100 \% \mathrm{D}_{2} \mathrm{O}$ in a 5-mm tube [34]. In our experiments for each peptide, the duration of the gradient was $2.25 \mathrm{~ms}$, the time between the two pulse gradients in the pulse sequence was set to $200 \mathrm{~ms}$, and the recovery delay between the bipolar gradients was set to 
$100 \mu \mathrm{s}$. The methyl groups with signals between 1.0 and 0.80 ppm were used for integration. Fitting of the exponential curves obtained from experimental data was carried out with KaleidaGraph (Synergy Software, Version 3.5), as described [30]. A final concentration of $1 \%$ of dioxane, which was assumed to have a hydrodynamic radius $R_{\mathrm{h}}=2.12 \AA$ [34], was added to the solutions of each of the peptides to have a comparison for estimating their sizes.

\subsection{3. $2 \mathrm{D}-{ }^{1} \mathrm{H}-\mathrm{NMR}$ Spectra}

Two-dimensional spectra in each dimension were acquired in phase-sensitive mode by using the time-proportional phase incrementation technique (TPPI) and a spectral width of $7801.69 \mathrm{~Hz}$ [35]; the final concentration was the same used in the $1 \mathrm{D}-{ }^{1} \mathrm{H}-\mathrm{NMR}$ experiments. Standard total correlation spectroscopy (TOCSY) (with a mixing time of $80 \mathrm{~ms}$ ) [36] and nuclear Overhauser effect spectroscopy (NOESY) experiments (with a mixing time of $250 \mathrm{~ms}$ ) [37] were performed with a data matrix size of $4 \mathrm{~K} \times 512$. The DIPSI (decoupling in the presence of scalar interactions) spin-lock sequence [38] was used in the TOCSY experiments with $1 \mathrm{~s}$ of relaxation time. Typically, 64 scans were acquired per increment in the first dimension, and the residual water signal was removed by using the WATERGATE sequence [39]. NOESY spectra were collected with 96 scans per increment in the first dimension, with the residual water signal removed again by the WATERGATE sequence and $1 \mathrm{~s}$ of relaxation time. Data were zero-filled and resolution-enhanced in each dimension, with a square sine-bell window function optimized in each spectrum, baseline-corrected, and processed with Bruker TopSpin 3.1. The ${ }^{1} \mathrm{H}$ resonances were assigned by standard sequential assignment processes [40]. The chemical shift values of $\mathrm{H}_{\alpha}$ protons in random-coil regions were obtained from tabulated data, corrected by neighboring residue effects $[41,42]$ and taking into account the phosphorylation of Thr68 [43,44] for the corresponding peptide.

\subsection{Molecular Docking}

Molecular docking was performed using AutoDock Vina (Version 1.1.2) [45], largely following a protocol we have previously described for screening NUPR1 sequence fragments [24]. The structure of $\Delta \operatorname{Imp} \alpha 3$ was modeled on the basis of the Protein Data Bank (PDB) entry $5 \times 8 \mathrm{~N}[46]$, which reports the X-ray structure of monomeric Imp $\alpha 1$ bound to the NLS of the Epstein-Barr virus EBNA-LP protein. The search volume was centered on the macromolecule and had the size $50 \AA \times 90 \AA \times 90 \AA$, which was sufficient to carry out a blind search on the whole protein surface.

The peptides used in our experiments encompassed residues 53-74 of NUPR1, with a number of rotatable dihedral angles ranging from 85 to 91 . Their conformational space was too large to be reasonably treated by molecular docking; therefore, we followed a two-fold approach [47] that consisted in reducing the number of degrees of freedom and using a longer search protocol. The number of rotatable dihedrals was halved by considering the reduced sequence that encompasses residues 63-71 of NUPR1, and therefore, it includes only the core region of the NLS. These shorter peptide sequences were capped with an acetyl and N-methyl group at the two main chain endings, to mimic the fact that they are internal portions of the sequence of the protein, as well as of their full-length parent peptides. An extensive search was performed with very high exhaustiveness, 16 times larger than the recommended default value [48].

\section{Results}

\subsection{The Isolated wt NLS-NUPR1 and Its Mutants Were Monomeric and Disordered in Aqueous Solution}

We first determined the conformational propensities of isolated peptides by using CD and NMR. We did not use fluorescence to characterize their conformational features, because the peptides only have a single tyrosine at their $\mathrm{N}$ terminus, whose maximum wavelength $(\sim 308 \mathrm{~nm})$ does not change under different environments in solutions [49]. The CD spectra of isolated peptides did show an intense minimum at $200 \mathrm{~nm}$ (Figure S1), indicating that they were mainly in a random-coil conformation. 
This was further confirmed by $1 \mathrm{D}-{ }^{1} \mathrm{H}-\mathrm{NMR}$ spectra, which showed, for all the peptides, a clustering of the signals of all the amide protons between 8.0 and $8.5 \mathrm{ppm}$ (Figure S2) and grouping of the methyl protons between 0.8 and $1.0 \mathrm{ppm}$, which is a feature of disordered polypeptide chains [40].

The peptides were monomeric, as concluded from the values of $D$ measured by the DOSYs and the calculation of the estimated $R_{\mathrm{h}}$ from a random-coil polypeptide according to an exponential law [29] (Table 1).

To further confirm the disordered nature of the peptides, we also carried out homonuclear 2D-1 H-NMR experiments (Tables S1-S8). For all peptides, NOEs between the $\mathrm{H}_{\alpha}$ protons of Arg56 or Ser58 and the $\mathrm{H}_{\delta}$ of the two following residues (Pro57 and Pro59, respectively) were always observed (Figure 1); these findings suggest that the Arg56-Pro57 and Ser58-Pro59 peptide bonds predominantly adopted a trans-conformation in all the peptides (other minor signals were not observed). Two lines of evidence confirmed the disordered nature of the peptides (further pinpointing the findings from far-UV $\mathrm{CD}$ (Figure S1) and the 1D- ${ }^{1} \mathrm{H}-\mathrm{NMR}$ spectra (Figure S2)). First, the sequence-corrected conformational shifts $(\Delta \delta)$ of $\mathrm{H}_{\alpha}$ protons [40-44] were within the commonly accepted range for random-coil peptides $(\Delta \delta \leq 0.1 \mathrm{ppm})$ (Tables S1-S8). It is interesting to note at this stage that, in the phosphorylated Thr68 of the pT68 peptide, the signals from the $\mathrm{H}_{\beta}$ protons were downfield shifted when compared to those of the wt peptide (4.58 versus $4.15 \mathrm{ppm}$, respectively), as well as the chemical shift of the amide proton: 8.62 versus 8.33 , respectively (Tables S1 and S3), as it has been reported to occur for phosphorylated threonines $[43,44]$, thus confirming the phosphorylation of this particular threonine and not of the other one in the sequence, Thr54. Second, in any of the peptides, no long- or medium-range NOEs were generally detected but, rather, only strong sequential ones $(\alpha \mathrm{N}(i, i+1))$ (Figure 1). Only in the pThr68 peptide and in the four phospho-mimics (T68E, K65AT68E, T68EK69A, and K65AT68EK69A peptides), we observed a weak NOE $(\mathrm{NN}(i, i+1))$ between the amide protons of Val67 and Thr68 (Figure S3). This NOE, although weak when compared with the intensity of sequential $\alpha \mathrm{N}(i, i+1)$ NOEs, is a fingerprint signature of turn-like conformations [40].

Although there are some isolated short peptides that are partially structured (such as the isolated Ribonuclease S peptide [33,40]), our findings by CD and NMR indicate that the isolated NLS-NUPR1 peptides were mainly disordered in aqueous solution when isolated.

\subsection{The NLS-NUPR1 Peptides Bound to Both Impa3 and $\triangle I m p \alpha 3$}

In the present work, we measured the affinity of intact NUPR 1 for $\triangle \operatorname{Imp} \alpha 3$, obtaining a value for the dissociation constant of $0.4 \mu \mathrm{M}$ (Figure S4), and we have previously measured the affinity of intact NUPR1 for Imp $\alpha 3$, and a value of $1.4 \mu \mathrm{M}$ has been obtained (shown in Figure S4; for a comparison, [50]). Furthermore, we tried to dissect the affinity of the NLS region of NUPR1 for Imp $\alpha 3$ by using a "divide and conquer" approach with the peptides comprising the region. The interaction between full-length NUPR1 and its mutants with Imp $\alpha 3$ and $\Delta \operatorname{Imp} \alpha 3$ was the focus of this study, but instead, we employed NLS peptides to elucidate the binding mechanism to Imp $\alpha 3$. The reason behind such an approach relies in the fact that we have observed that, very often, mutations at any place of the polypeptide length of NUPR1 result in a poor expression of the corresponding mutant, and mutations in some positions lead to no expression at all [24].

First, we decided to investigate a possible interaction between the NLS NUPR1 peptides and Imp $\alpha 3$ in vitro by using fluorescence and $C D$. As a representative example, we describe our findings for the wt peptide. We observed changes in the fluorescence spectrum of this peptide after excitation at $280 \mathrm{~nm}$ (whereas there were no changes at $295 \mathrm{~nm}$ ); that is, the additional spectrum obtained from the spectra of isolated wt peptide and either $\operatorname{Imp} \alpha 3$ or $\Delta \operatorname{Imp} \alpha 3$ was different to those of their respective complexes (Figure 2A). These results indicate that tyrosine residues of at least one of the biomolecules (peptides with either Imp $\alpha 3$ or $\Delta \operatorname{Imp} \alpha 3$ ) were mainly involved in the binding. The changes were small for Imp $\alpha 3$, and there were no changes for $\Delta \operatorname{Imp} \alpha 3$; furthermore, thermal denaturations followed by fluorescence did not show a variation in the apparent thermal denaturation midpoint for both Imp $\alpha 3$ and $\triangle \mathrm{Imp} \alpha 3$ (Figure S5). On the other hand, the comparison of the additional spectrum and that of 
the complex obtained by far-UV CD did show differences (both for $\operatorname{Imp} \alpha 3$ and $\Delta \operatorname{Imp} \alpha 3$ ), indicating that there were changes in the secondary structure of at least one of the macromolecules upon binding (Figure 2B); however, there were no differences in the determined thermal denaturation midpoint for isolated Imp $\alpha 3$ (or $\Delta \operatorname{Imp} \alpha 3$ ) and that of the complex (Figure S5). It is important to note that the far-UV CD region is sensitive to elements of secondary structures ( $\alpha$-helix and $\beta$-sheet); however, local structural elements and nonregular structures might also be present, which could be masked by the presence of long disordered regions. The above results indicate that there was binding between the wt peptide and both importins, but the binding did not induce large changes in the structures of both macromolecules.

The situation was slightly different in the case of the Imp $\alpha 3$ and $\Delta \operatorname{Imp} \alpha 3$ complexes with the other mutant peptides. As an example, we described our results with the K65A peptide, and the findings for the other peptides were basically similar to those described here. Where the far-UV CD spectra of the addition and that of the complex with both importins also showed small differences (Figure S6A,B), the fluorescence spectra did not have modifications (either by excitation at 280 or $295 \mathrm{~nm}$ ) (Figure S6C,D). In general, for the mutant peptides, the changes were smaller than for the wt peptides.

The above experiments were sufficient to conclude that the NLS-NUPR1 peptides interacted with $\operatorname{Imp} \alpha 3$ or $\Delta \operatorname{Imp} \alpha 3$, but we also carried out ITC experiments to measure the binding affinity. The results (Table 2 and Figure 3) indicate that: (i) the highest affinity towards either Imp $\alpha 3$ or $\Delta \operatorname{Imp} \alpha 3$ was that observed for the wt peptide, (ii) the affinity for most of the peptides was higher for binding to $\Delta \operatorname{Imp} \alpha 3$ (the only exceptions were the T68EK69A and pT68 peptides), (iii) removal of Lys65 or Lys69 residues decreased the affinity (and the variations in affinity were higher for $\Delta \operatorname{Imp} \alpha 3$ than for Imp $\alpha 3$ ), and (iv) the phosphorylation or mutation to Glu (phospho-mimics) of Thr68 decreased the affinity by almost one order of magnitude when compared to the other mutations for both importin species. Therefore, the ITC findings mirrored the results obtained by fluorescence: there were lesser structural changes (as reported by fluorescence) in the binding of the peptide mutants than for the wt one, and the affinity of the former peptides for importins was lower (Table 2).

Taking together all these findings, we conclude that the isolated region of NUPR1 comprising its NLS was capable of binding to Imp $\alpha 3$ and that this binding was strongly modulated by the phosphorylation state of Thr68 and the charges at positions Lys65 and Lys69. 


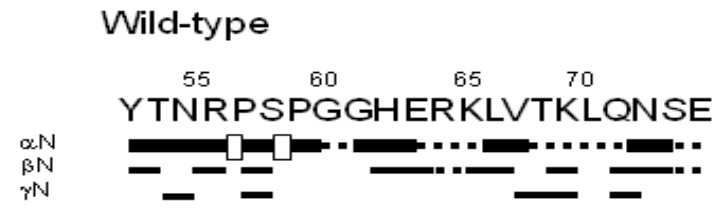

K69A

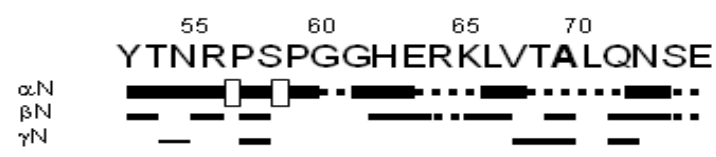

pT68

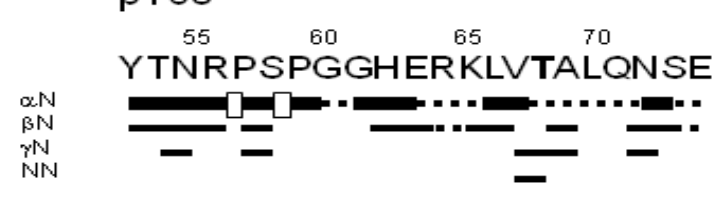

K65A T68E

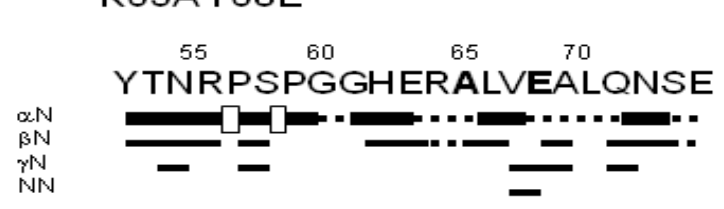

T68EK69A

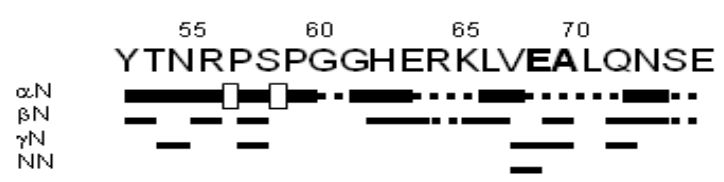

K65A

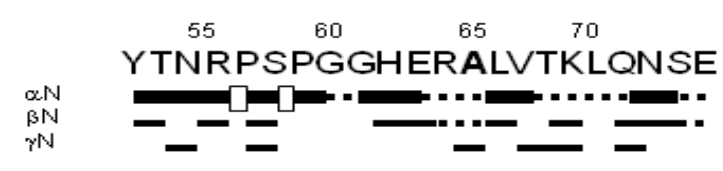

T68E

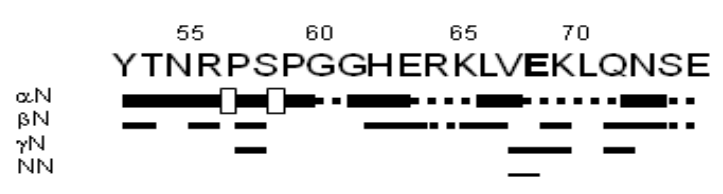

K65AT68EK69A

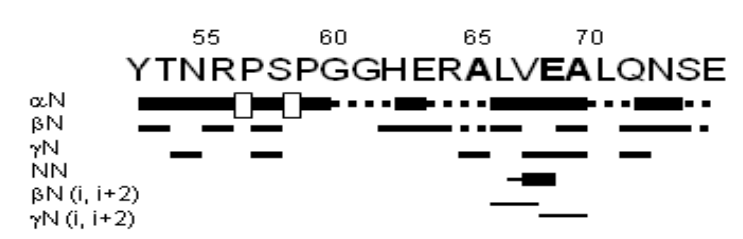

Figure 1. NMR structural characterization of the nuclear localization sequence (NLS) NUPR1 peptides. Nuclear Overhauser effects (NOEs) are classified into strong, medium, or weak, as represented by the height of the bar underneath the sequence; the signal intensity was judged by visual inspection from the nuclear Overhauser effect spectroscopy (NOESY) experiments. The symbols $\alpha \mathrm{N}, \beta \mathrm{N}, \gamma \mathrm{N}$, and NN correspond to the sequential contacts (that is, for instance, the NN corresponds to the $\mathrm{NN}(i, i+1)$ contacts). The corresponding $\mathrm{H}_{\alpha}$ NOEs with the $\mathrm{H}_{\delta}$ of the following proline residues are indicated by an open bar in the row corresponding to the $\alpha \mathrm{N}$ contacts. The dotted lines indicate NOE contacts that could not be unambiguously assigned due to signal overlap. The numbering of the residues corresponds to that of the whole sequence of NUPR1. 

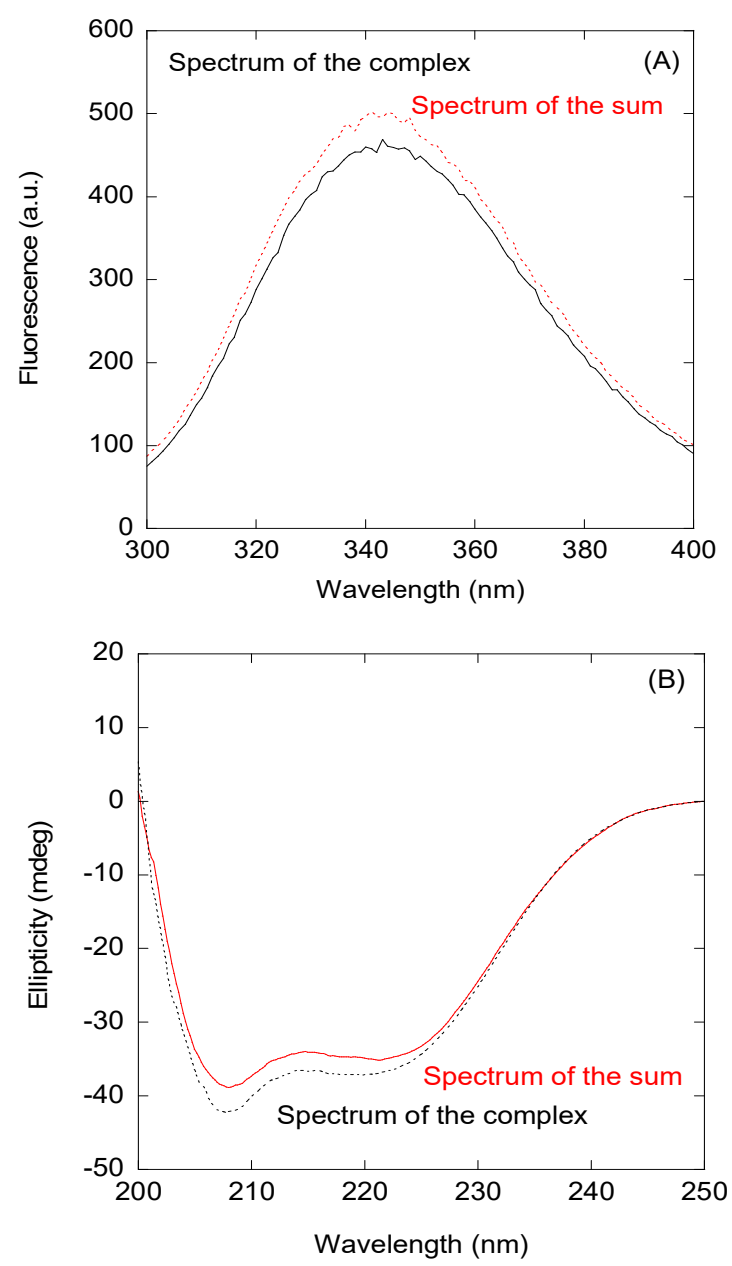

Figure 2. Binding of the wild-type (wt) peptide to importin $\alpha 3(\operatorname{Imp} \alpha 3)$ monitored by spectroscopic techniques: (A) Fluorescence spectrum obtained by excitation at $280 \mathrm{~nm}$ of the complex between Imp $\alpha 3$ and the wt peptide and the addition spectrum obtained by the sum of the spectra of both isolated macromolecules. (B) Far-UV CD (ultraviolet circular dichroism) spectrum of the complex between the Imp $\alpha 3$ and wt peptides and the additional spectrum obtained by the sum of the spectra of both isolated macromolecules.

\subsection{Binding Regions in the Docking of NUPR1 Peptides to Importins}

Since we have shown that there was binding between the peptides and both importins, and we have identified the most important residues for attaining such binding, we performed molecular docking to determine details on the location and binding energy of the NUPR1 peptides on the surface of Imp $\alpha 3$. When applied to our case, the docking techniques possess three caveats that are worth mentioning explicitly. First, even in the case of our relatively short peptides, the number of degrees of freedom to be considered is too large to be computationally tractable. This number was halved by considering reduced sequences (nine amino acids, corresponding to residues 63-71 of NUPR1), which included all the mutation sites plus at least two more residues at each end. Second, it is impossible with this technique to discriminate differences in the binding between $\operatorname{Imp} \alpha 3$ and $\Delta \operatorname{Imp} \alpha 3$, and therefore, only the latter protein structure was considered. Third, molecular docking does not take into account the dynamics of a protein-ligand complex, which could also contribute to the binding. Keeping in mind these limitations, the protein surface was blindly explored by considering a volume that included the whole structure and using a high exhaustiveness of search that is equivalent to running multiple $(>10)$ distinct simulations. 
Figure 4 summarizes the predictions obtained in our docking calculations. In particular, Figure 4A illustrates the energetically most favorable poses obtained for the wild-type (capped) sequence ERKLVTKLQ mapped on the surface of importin. The best eight poses are reported for clarity and to obtain a more direct comparison with the cluster of the single best pose for each of the eight different peptides (see below, Figure 4D). The results clearly show that the most favorable binding modes cluster into a single location that consists of the major NLS-binding site, located on ARM repeats 2-4. As shown in Figure 4B, the best structure found for our peptide sequence overlaps quite remarkably with that of the NLS of the Epstein-Barr virus EBNA-LP protein, whose structure has been previously determined in crystallography [46]. A number of different amino acids participate in the binding, including some key tryptophan residues (see the details in Figure 4C) that are known to play an important role in the formation of the importin-cargo complex. The binding energy in the docking for the most favorable conformation was $-7.2 \mathrm{kcal} / \mathrm{mol}$, indicating a moderate affinity in the low micromolar range. Compared to the experimental values found for the whole wild-type sequence YTNRPSPGGHERALVTKLQNSE $(-7.87$ and $-8.22 \mathrm{kcal} / \mathrm{mol}$ for Imp $\alpha 3$ and $\Delta \operatorname{Imp} \alpha 3$, respectively; see Table 2), this finding indicates that the reduced docked sequence provides the major contribution to the binding-free energy of the full-length peptide.

Figure $4 \mathrm{D}$ shows the best docking poses obtained for the seven mutant sequences compared to the wt one, which is also reported. Again, in this case, all the most favorable binding modes (and, more generally, even the first ten docking poses for each peptide species) clustered in the same location correspond to the major NLS-binding site. This observation suggests that the mutations do not modify essentially the binding location of the peptides but only their affinity towards importin. The calculated binding energies ranged from -5.6 to $-6.6 \mathrm{kcal} / \mathrm{mol}$, indicating that any of the explored mutations reduced the binding affinity with respect to the wt sequence, in agreement with our experimental results (Table 2). We observed a poor correlation between the computational and experimental rankings of the mutated peptides in terms of affinity towards the protein, although this could reasonably be explained, because the experimental binding energies are, in most cases, very close to each other (Table 2). This finding did not let us push too far the interpretation of our results in terms of the molecular details that assist the binding. Nevertheless, the contribution of the protein tryptophan residues to the binding still seemed to be, in all cases, an important determinant (even though we did not observe changes in the fluorescence spectra (either by excitation at 280 or $295 \mathrm{~nm}$ ) when binding for some of the mutant peptide sequences was explored, Figure S6).

To sum up, a number of important conclusions can be drawn from the docking results reported: (i) all the sequences investigated interacted with the same region of importin; (ii) this region matched unambiguously with the major NLS-binding site of the protein; (iii) the ligand with the highest binding affinity corresponded to the wt sequence of NUPR1 (in agreement with the experimental results from ITC; Table 2); (iv) the major contribution to the binding energy of the parent peptides (i.e., those used in this work) was due to such a restricted sequence portion, which includes only nine residues (and this region includes Lys65, Thr68, and Lys69); (v) this essential sequence fragment corresponded to the core region of the predicted NLS of NUPR1; (vi) the binding region roughly mapped around Thr68 (where the residue name and number refers to wild-type, intact NUPR1 numbering), which therefore appears to be a key amino acid; and (vii) the most favorable predicted structure for the NLS region of wild-type NUPR1 essentially overlapped with the conformation of the NLS of a different protein (the Epstein-Barr virus EBNA-LP protein) determined in crystallography. 
Table 2. Thermodynamic parameters at $298 \mathrm{~K}$ in the binding reaction of NLS NUPR1 peptides to the two importin species a .

\begin{tabular}{|c|c|c|c|c|c|c|c|c|}
\hline \multirow[b]{2}{*}{ Peptide } & \multicolumn{4}{|c|}{$\operatorname{Imp} \alpha 3$} & \multicolumn{4}{|c|}{$\Delta \operatorname{Imp} \alpha 3$} \\
\hline & $K_{\mathrm{d}}(\mu \mathrm{M})$ & $\Delta H(\mathrm{kcal} / \mathrm{mol})$ & $-T \Delta S(\mathrm{kcal} / \mathrm{mol})$ & $n$ & $K_{\mathrm{d}}(\mu \mathrm{M})$ & $\Delta H(\mathrm{kcal} / \mathrm{mol})$ & $-T \Delta S(\mathrm{kcal} / \mathrm{mol})$ & $n$ \\
\hline wt & 1.7 & 0.8 & -8.7 & 0.9 & 0.95 & -3.7 & -4.5 & 1.0 \\
\hline K65A & 3.9 & -2.8 & -4.6 & 1.4 & 2.7 & -10.2 & 2.6 & 1.4 \\
\hline K69A & 11 & -10.8 & 4.0 & 1.3 & 7.6 & -21.3 & 14.3 & 1.4 \\
\hline T68E & 22 & -11.1 & 4.7 & $(1)$ & 12 & -17.5 & 10.8 & $(1)$ \\
\hline K65AT68E & 21 & -7.8 & 1.4 & (1) & 14 & -17.9 & 11.3 & (1) \\
\hline T68EK69A & 17 & -7.5 & 1.0 & (1) & 17 & -21.2 & 14.7 & (1) \\
\hline K65AT68EK69A & 27 & -16.3 & 9.1 & (1) & 24 & -28.5 & 22.2 & (1) \\
\hline pT68 & 27 & -14.8 & 3.6 & (1) & 29 & -28.2 & 22.0 & (1) \\
\hline
\end{tabular}

a Relative error in $K_{\mathrm{d}}$ (dissociation constant) is $30 \%$, absolute errors in $\Delta H$ (enthalpy) and $-T \Delta S$ (entropy) are 0.5 and $0.7 \mathrm{kcal} / \mathrm{mol}$, respectively, and absolute error in $\mathrm{n}$ (the stoichiometry) is 0.2 . The parenthesis in $\mathrm{n}$ values indicate that this parameter had to be fixed in order to get convergence in the fit due to low affinity. 

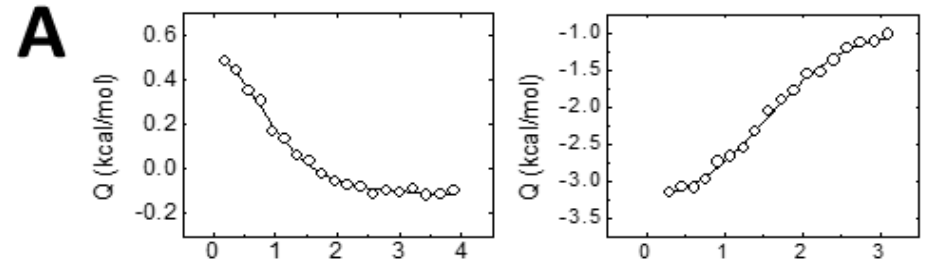

$[\mathrm{WT}]_{T} /[\mathrm{Impa} \cdot 3]_{T}$

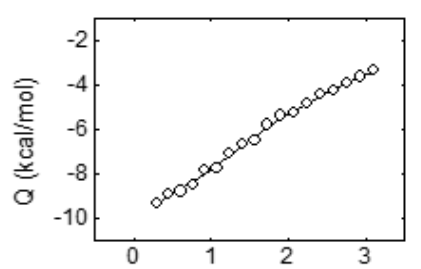

$[\mathrm{K} 69 \mathrm{~A}]_{T} / \mathrm{IImpa3}$,

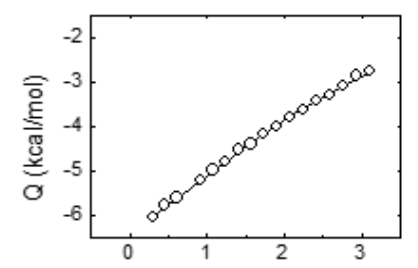

[K65AT68E ]//Im pa3]

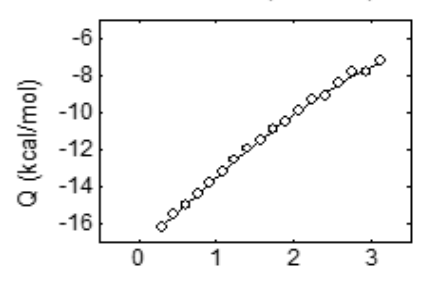

[K65A T68EK69A]//IImpa3]

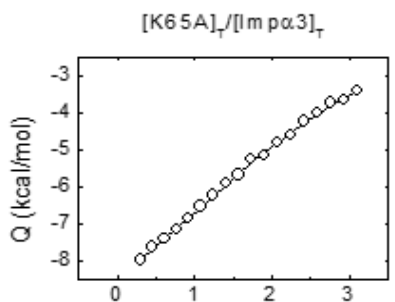

$[\mathrm{T} 68 \mathrm{E}]_{\mathrm{T}} /[\mathrm{Im} \mathrm{p} \alpha 3]_{T}$

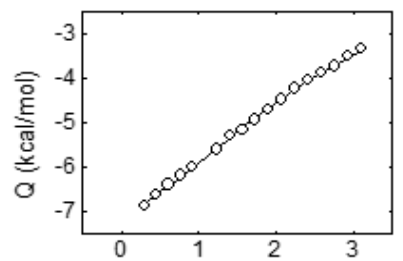

[T68EK69A $]_{T} /[\mathrm{Impa3}]_{T}$

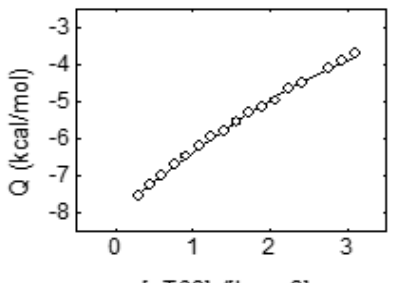

B

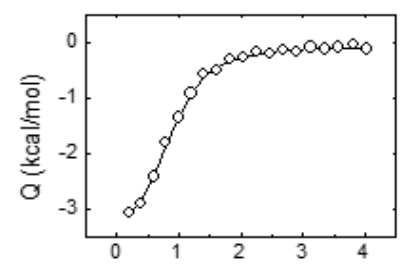

$[W T]_{T} /[\Delta \mid m p a .3]_{Y}$

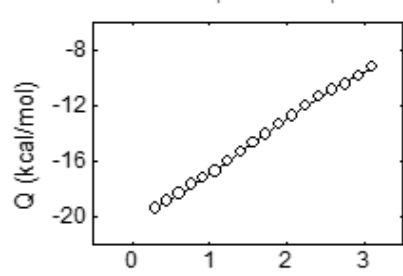

$[\mathrm{K} 69 \mathrm{~A}]_{T} /[\Delta \mathrm{mpa.3}]_{\mathrm{T}}$

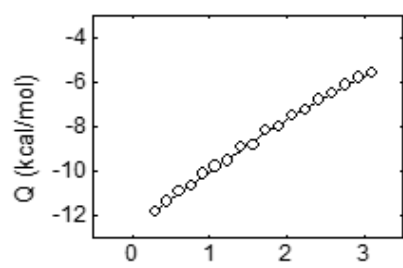

[K65A T68E] $/\left[\Delta \mathrm{Imp} \mathrm{a3]_{T }}\right.$

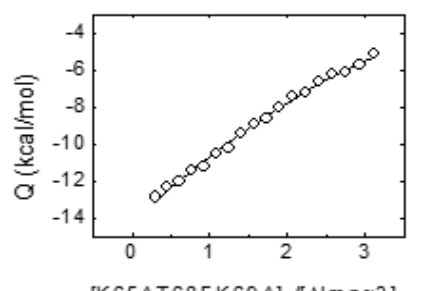

[K65AT68EK69A] [LAM P03

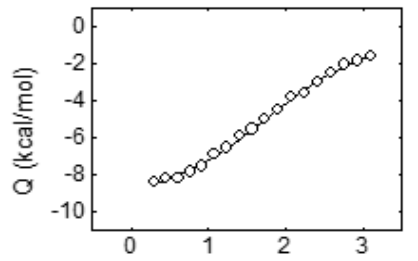

$[K 65]_{T} /[\Delta m p a 3]_{r}$

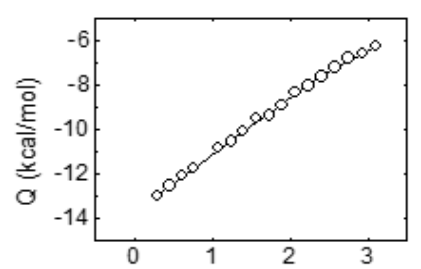

$[\mathrm{T68E}]_{\mathrm{T}} /[\Delta \mathrm{Impa} 3]_{\mathrm{r}}$

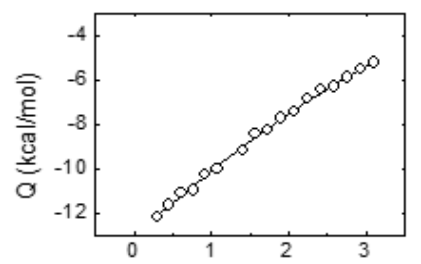

[T68EK69A $]_{T}[\Delta I m \text { p a } 3]_{T}$

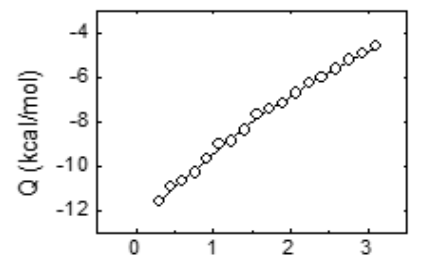

$[\mathrm{pT} 68]_{\mathrm{T}} /\left[\mathrm{\Delta lmpa3]_{T }}\right.$

Figure 3. The interaction of the wt and mutant NLS NUPR1 peptides with both importins as measured by isothermal titration calorimetry (ITC). Interaction isotherms (ligand normalized heat effect per injection as a function of the ligand:protein molar ratio) with Imp $\alpha 3$ (A) and $\Delta \operatorname{Imp} \alpha 3$ (B) are shown. Binding parameters were estimated by a nonlinear least-squares regression data analysis of the interaction isotherms applying a single ligand binding site model, implemented in Origin 7.0. 

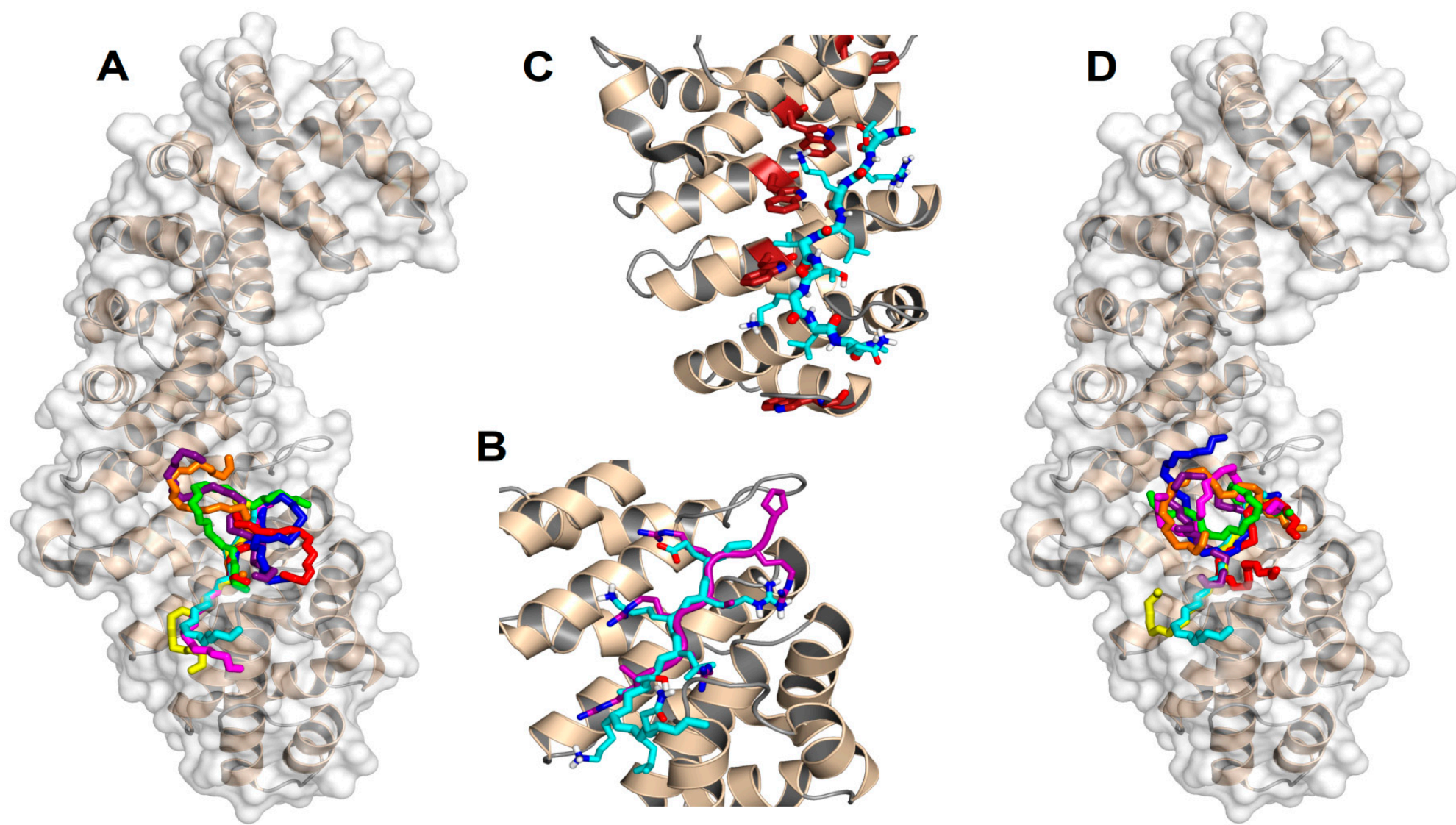

Figure 4. Predicted docking poses for the NLS of NUPR1 on importin. (A) Backbone $\left(-\mathrm{N}-\mathrm{C}^{\alpha}-\mathrm{C}-\right.$ atoms) representation of the best eight docking poses on $\triangle \mathrm{Importin}$ for the wt sequence ERKLVTKLQ (the $\mathrm{N}$ terminus is on the top), which constitutes the core region for the NLS of NUPR1. (B) Most favorable binding pose for the same sequence (cyan), compared to the crystallographic conformation [46] of the NLS of the Epstein-Barr virus EBNA-LP protein (purple). For clarity, atoms are shown in standard colors only in the side chains of the two peptides, and the main-chain $\mathrm{O}$ and $\mathrm{H}$ atoms are omitted; apolar $\mathrm{H}$ atoms are not present. (C) Trp residues (brown) in the major NLS-binding site of importin play a key role in the binding of the most favorable conformation of the NLS of wild-type NUPR1. The view is slightly rotated with respect to previous representations to evidence the tryptophan side chains. (D) Most favorable docking poses for the eight peptide sequences: wild type (cyan), K65A (magenta), K69A (yellow), T68E (blue), K65AT68E (red), T68EK69A (green), K65AT68EK69A (orange), and pT68 (violet). PyMol was used for all displays. 


\section{Discussion}

\subsection{Molecular Mechanisms for Impa3 Recognition of NUPR1: The Influence of Lys65 and Lys69}

In this work, we tried first to find out whether the theoretically predicted NLS region of NUPR1 was capable of binding in isolation to Imp $\alpha 3$. Second, we tried to elucidate, for the first time, the molecular bases behind the binding of an NLS region of an IDP to an importin. Our results indicate that the isolated, wild-type NLS region of NUPR1 interacted with the intact Imp $\alpha 3$ and $\Delta \operatorname{Imp} \alpha 3$, with an affinity similar to that for intact NUPR1 (1.4 $\mu \mathrm{M}$, Figure S4), and within the same range measured for the affinities to natural partners of NUPR1 [22,24,51] and synthetic molecules [23,52]. Furthermore, our results also address the molecular importance of IBB in the binding of cargos to importins.

As it happens for the intact NUPR1 (whose dissociation constants are $1.4 \mu \mathrm{M}$ for Imp $\alpha 3$ and $0.44 \mu \mathrm{M}$ for $\Delta \operatorname{Imp} \alpha 3$ (Figure S4)), the wt peptide bound to $\Delta \operatorname{Imp} \alpha 3$ with a two-fold larger affinity $(0.95 \mu \mathrm{M})$ than that for Imp $\alpha 3$ (Table 2$)(1.7 \mu \mathrm{M})$. These findings allow us to draw several conclusions. First, the presence of the IBB region (which contains a large quantity of lysine amino acids) exerts an autoinhibitory effect, and the domain hampers the entrance of the NLS peptide into the major NLS-binding region of Imp $\alpha 3$, as it has been suggested in other studies with well-folded proteins [9]. However, this is the first time such a hypothesis is tested in an IDP. Modulation of the assembly complex formation between importins and their cargos has been attributed to the IBB domain [4]; this domain has been found to be involved even in the formation of a homodimeric species between importins [53], with a reduced ability to bind cargos. Second, although the affinities of the wt peptide for both importins were smaller than those for intact NUPR1, many of the interactions implicated in the binding to importin could be ascribed to a region comprised within the wt peptide, as concluded from the similarities among the dissociation constants (0.44 (intact NUPR1) and $0.95 \mu \mathrm{M}$ (wt peptide) for $\Delta \operatorname{Imp} \alpha 3$ and 1.4 (intact NUPR1) and $1.7 \mu \mathrm{M}$ (wt peptide) for Imp $\alpha 3$ ). Third, given the similarities among the affinity constants for Imp $\alpha 3$ of the wt peptide and NUPR1, the peptide could be used as a lead compound to design an inhibitor of its nuclear translocation.

We have previously shown in vivo that a mutant of NUPR1 at positions Lys65, Lys69, Lys76, and Lys77 is present through the whole cell, whereas the wild-type NUPR1 species is localized exclusively into the nucleus [25]. In this work, we have found that the mutation Lys65Ala decreased two-fold the affinity for Imp $\alpha 3$, and the mutation Lys69Ala decreased six-fold the affinity. Thus, the decrease in the affinity was larger with the removal of Lys69, probably indicating that this residue makes more contacts with importin, as pinpointed by our docking models. In fact, we observed in the simulation that both lysine residues were involved in hydrophobic and polar contacts (the latter with their $\mathrm{NH}_{3}{ }^{+}$moieties), with residues of importin $\alpha$. The removal of the long side chains would disfavor those contacts, thus decreasing the affinity (Table 2). The importance of lysines is key in determining the binding to importins of other well-folded proteins through their disordered NLS regions, as shown by several structural studies $[3,8,54,55]$. It could be thought that our study does not provide new mechanistic insight into the function of importins, because the results obtained with an IDP pinpoint, for the first time, the importance of positive charges (as it happens in folded proteins) in the binding of their cargos; however, to the best of our knowledge, this is the first reported case where the importance of such residues is addressed in vitro for the NLS of an IDP, and our results acquire more relevance considering recent findings, where it has been suggested that IDPs do not require the presence of importins to be translocated into the nucleus, although demonstrated mostly for acidic proteins [56]. Then, our results indicated that IDPs require the help of importins to be translocated into the nucleus, and it seems that the rules governing such processes are similar to those observed in well-folded proteins.

The same decrease in affinity was observed for the K65A and K69A peptides towards $\Delta \operatorname{Imp} \alpha 3$, but, compared to the wt peptide, the variation was larger than that observed for both mutants with Imp $\alpha 3$ (Table 2). Furthermore, as it happens with the intact importin, the decrease in affinity was larger for the K69A peptide. These findings indicate that, although the IBB region maintains its independence 
within the whole Imp $\alpha 3$ in terms of conformation, its removal may either alter the structure of some regions of the ARM repeats involved in the major NLS-binding site (which relies on hydrophobic contacts to anchor the cargo, therefore altering its docking) or, alternatively, IBB removal may change the whole protein dynamics and its stability.

\subsection{Molecular Mechanisms for Impa3 Recognition of NUPR1: The Influence of Thr68 and Its Phosphorylation-Triggered Conformational Switch}

Apart from the importance of the two lysines of NUPR1 in the binding to importins, we also wanted to address the importance of Thr68. It is well-established that Thr68 is a key residue in the binding of NUPR1 to any partner, either natural or synthetic [22-24,57]; in fact, together with Ala33, it constitutes one of the two hotspot regions of NUPR1. We decided to address such a question by following two approaches: (i) we mutated Thr68 to Glu to have the phospho-mimics, and (ii) we synthesized a peptide with the phosphorylated Thr (pT68 peptide).

Among all the mutants explored, the peptide with the smallest affinity for $\operatorname{Imp} \alpha 3$ or $\Delta \operatorname{Imp} \alpha 3$ $(\sim 30 \mu \mathrm{M}$ for both species) was the pThr68 peptide (Table 2). Phosphorylation affects the binding probably by inhibiting long-range electrostatic contacts with both importins. Where the affinity of the wt peptide for $\Delta \operatorname{Imp} \alpha 3$ was larger, the changes due to the addition of the phosphate group in the pThr68 peptide were even larger, further pinpointing subtle structural changes in the major NLS-binding region upon removal of the IBB. Around a third of the eukaryotic proteins can be phosphorylated, and the majority of those phosphorylation sites belong to intrinsically disordered regions because of their accessibility to kinases [14]. Phosphorylation is a key regulatory mechanism in translation, transcription, and other processes.

The phospho-mimetic peptide of NLS-NUPR1, the T68E peptide, also showed a smaller affinity for both importins than the wt one ( $22 \mu \mathrm{M}$ for Imp $\alpha 3$ and $12 \mu \mathrm{M}$ for $\Delta \operatorname{Imp} \alpha 3$, Table 2), but the decrease was not as large as that in the pT68 peptide ( $27 \mu \mathrm{M}$ for Imp $\alpha 3$ and $29 \mu \mathrm{M}$ for $\Delta \operatorname{Imp} \alpha 3$, Table 2), indicating that the phospho-mimics did not cause the same effect as phosphorylation. Phosphorylation at Thr68 replaces the neutral $\mathrm{OH}$ (hydroxyl) group with a tetrahedral $\mathrm{PO}_{4}{ }^{2-}$ (phosphoryl group) with two negative charges, which modifies the electrostatic, chemical, and steric properties of the threonine environment. The double-negative charge of the $\mathrm{PO}_{4}{ }^{2-}$ and its large surrounding hydration shell make the situation chemically different from the Glu phospho-mimic, which has a smaller hydration shell and a single negative charge. Differences among the affinities of phospho-mimics and phosphorylated threonines for a well-folded protein have been also observed in the affinities measured in other protein systems [58], as well as in other IDPs [59].

The values of the affinity constants of the K65AT68E and T68EK69A peptides were similar to that of the T68E peptide (Table 2). This finding indicates that: (i) the effect of Thr68Glu in the binding to importins surpassed those caused by substitutions of the single lysines (and then, Thr68 must have a greater importance in the interaction), and (ii) the effect of removing a lysine when the threonine is phospho-mimicked is not additive for the double mutants, probably because the remnant lysine establishes electrostatic interactions with the glutamic residue. However, the accumulation of the three mutations (in the K65AT68EK69A peptide) led to a large decrease of the affinity constant (Table 2), further highlighting the influence of electrostatic effects between the lysines and the phospho-mimics in the bindings with the two importins. Other studies of phosphorylation of threonines in IDPs indicate that the proximity of arginines can stabilize the charge of the phosphoryl moiety and the stabilization of turn-like structures [60]. We suggest that, in the case of NUPR1, lysines, instead of arginines, would play the role of stabilizing the conformation.

Interestingly enough, the peptides containing the phospho-mimic mutation (T68E) or the phosphorylated Thr68 (pT68 peptide) did show an NN(i,i+1) NOE (Figure 1) between Val67 and phosphorylated Thr68 (or Glu68). We did not observe such a NOE in the intact NUPR1 when we assigned it [22]. It could be thought that the absence of such a NOE in the wt peptide may be due to the fact that the chemical shifts of the amide protons of those residues (Val67 and Thr68) were 
similar (Table S1), and then, the NOE could not be observed because of its proximity to the spectrum diagonal. However, the chemical shifts of amides of both residues in the K65A peptide were different enough (8.25 and $8.35 \mathrm{ppm}$ for Val67 and Thr68, respectively; Table S6) to allow for its detection, and nevertheless, we did not observe any NOE (Figure S3). Thus, the presence of such a NOE, although it is weak in intensity, indicates that, upon phosphorylation, the two residues populated a turn-like conformation [40]; the presence of this turn is further supported by the observation of $\beta \mathrm{N}(i, i+2)$ and $\gamma \mathrm{N}(i, i+2)$ NOEs and an additional $\mathrm{NN}(i, i+1)$ contact for the K65AT68EK69A peptide involving residues Leu66-Thr68 (Figure 1), due to the large, intrinsic propensity of alanine to populate helix-like conformations [61,62]. As the affinity of the peptides for both importins decreased when Thr68 was phosphorylated or was phospho-mimicked (Table 2), we can conclude that the decrease in the affinity of peptides upon phosphorylation was structurally related to a conformational switch around Thr68, as a consequence of the introduced negative charge, shifting the population at equilibrium from a random-coil conformation to a turn-like one. The decrease in affinity for both importins may be related to the reduction in entropy of the polypeptide chain upon acquisition of the turn-like conformation and a concomitant conformational energetic penalty for the binding. Interestingly enough, two decades ago, we showed by using FTIR (Fourier transform infra-red spectroscopy) and CD that the unspecific phosphorylation of the serines and threonines in NUPR1 led to a higher population of $\alpha$-helix- and/or turn-like conformations in the intact protein [21]; at the moment, however, we do not have any evidence for the biological importance of the particular phosphorylation of Thr68 in vivo. Nonetheless, we have recently shown that the mutation of Thr68 to Gln hampers the formation of several complexes of NUPR1 with other proteins involved in SUMOylation processes [50]. Our previous result is confirmed in this work by our new findings obtained with Thr68. Phosphorylation, as well as other post-translational modifications, can affect protein conformations: (i) on a local scale-for instance by affecting the population of cis proline isomers [63], (ii) determining a change of entropy of the conformational ensemble [64], (iii) modulating the binding to other macromolecules and triggering phase separation [65], (iv) in an allosteric manner, by affecting distant residues from the phosphorylation site [66], and, (iv) causing a conformational change [67,68]. Conformational switching affecting a threonine in several IDPs has been described $[59,69,70]$. For instance, the phosphorylation of Thr51 in the IDP prostate-associated gene protein increases the population of transient turn-like populations [70]; the difference with our results is that the turn-like structures in NUPR1 were stabilized in a much shorter polypeptide region, although we cannot rule out that phosphorylation at other sites of NUPR1 could help in stabilizing this conformation. On the other hand, the p27 protein, which modulates the mammalian cell cycle by the inhibition of cyclin-dependent kinases, contains some disordered regions, and the phosphorylation of residue Thr157 in breast cancer cells prevents its interaction with the nuclear import machinery, leading to the accumulation of this protein in the cytoplasm, whereas it is normally found in the nucleus [69]; however, no indication on the particular structure acquired upon phosphorylation at Thr157 has been provided. Finally, it is important to note that recent theoretical molecular dynamic simulations have shown that the binding of importin $\alpha$ to heterochromatin protein $1 \alpha$ is modulated by phosphorylation at residues in its importin-binding region [71].

Thr68 is, together with the polypeptide patch around Ala33, the hotspot region of NUPR1, involved in binding to its natural partners $[21,22,24,51]$ and to other synthetic molecules and macromolecules $[23,52,57]$. We have previously observed that the mutation of Thr68 to glutamine hampers the binding to those other molecules [24,51]. Such a mutation will probably cause a shift of the ensemble population from a random-coil towards turn-like conformations, and it is the adoption of such a local fold that hampers bindings to those other natural partners or synthetic molecules. Moreover, as the affinity of NUPR1 to its partners is basically the same in all cases described to date $[21,22,24,51,52,57]$, its binding features can also be modulated by phosphorylation at Thr68 at least partially, since the region around Ala33 is also involved in the binding. In addition, since this threonine is also associated with the binding of drugs strongly effective against pancreatic cancer in mice $[23,32]$, we hypothesize that the molecular effects of such drugs could be the induction of a stable 
fold (turn-like) by this polypeptide region, besides competitive steric hindrance, preventing binding to other natural partners of NUPR1, and hampering the protein cascades where it is involved.

\section{Conclusions}

We have described the interaction between the NLS region of NUPR1, a nuclear intrinsically disordered protein involved in cancer, and Imp $\alpha 3$ by using a series of peptides comprising that polypeptide patch. Binding to Imp $\alpha 3$ is modulated by the charges of Lys64 and Lys69 but, most importantly, by phosphorylation at Thr68, which constitutes an entropy-driven conformational switch, shifting the population of the dynamic ensemble towards a turn-like conformation. As Thr68 is also a hotspot for NUPR1 interactions, these results open the venue to modulating the binding to its partners by targeting this residue. Furthermore, it also suggests a possible mechanism for the action of drugs targeting NUPR1, which also bind through Thr68.

Supplementary Materials: The following are available online at http://www.mdpi.com/2218-273X/10/9/1313/s1, Figure S1: Structural features of NLS-NUPR1 peptides as monitored by far-UV CD, Figure S2: Structural features of NLS-NUPR1 peptides as monitored by $1 \mathrm{D}-{ }^{1} \mathrm{H}-\mathrm{NMR}$, Figure S3: The amide region of 2D- ${ }^{1} \mathrm{H}-\mathrm{NOESY}$ spectra of NLS-NUPR1 peptides, Figure S4: Interaction between (left) $\operatorname{Imp} \alpha 3$ and (right) $\triangle \operatorname{Imp} \alpha 3$ with full-length NUPR1 as observed by ITC, Figure S5: Thermal denaturation of the complexes followed by spectroscopic techniques, Figure S6: Interaction between $\operatorname{Imp} \alpha 3$ and $\Delta \operatorname{Imp} \alpha 3$ with K65A peptide measured by different spectroscopic techniques, Table S1: Chemical shifts $(\delta, \mathrm{ppm}$ from TSP) of wt peptide in aqueous solution ( $\mathrm{pH} 7.2,283 \mathrm{~K})$, Table S2: Chemical shifts $(\delta$, ppm from TSP) of K69A peptide in aqueous solution (pH 7.2, $283 \mathrm{~K})$, Table S3: Chemical shifts $(\delta, \mathrm{ppm}$ from TSP) of pT68 peptide in aqueous solution $(\mathrm{pH} 7.2,283 \mathrm{~K})$, Table S4: Chemical shifts $(\delta$, ppm from TSP) of T68EK69A peptide in aqueous solution ( $\mathrm{pH} 7.2,283 \mathrm{~K})$, Table S5: Chemical shifts ( $\delta$, ppm from TSP) of K65AT68E peptide in aqueous solution ( $\mathrm{pH} 7.2,283 \mathrm{~K}$ ), Table S6: Chemical shifts ( $\delta$, ppm from TSP) of K65A peptide in aqueous solution ( $\mathrm{pH} 7.2,283 \mathrm{~K})$, Table S7: Chemical shifts ( $\delta$, ppm from TSP) of T68E peptide in aqueous solution ( $\mathrm{pH} 7.2,283 \mathrm{~K})$, Table S8: Chemical shifts $(\delta, \mathrm{ppm}$ from TSP) of K65AT68EK69A peptide in aqueous solution ( $\mathrm{pH} 7.2,283 \mathrm{~K})$.

Author Contributions: Conceptualization, J.L.N., B.R., A.V.-C., O.A., and J.L.I.; methodology, J.L.N., B.R., A.V.-C., O.A., and J.L.I.; investigation, J.L.N., B.R., A.V.-C., M.P.-S., and A.J.-A.; data analysis, J.L.N., B.R., A.V.-C., and A.J.-A.; writing - original draft preparation, J.L.N., B.R., and A.V.-C.; writing-review and editing, J.L.N., B.R., J.L.I., M.P.-S., A.J.-A., O.A., and A.V.-C.; and funding acquisition, J.L.N., A.V.-C., O.A., and J.L.I. All authors have read and agreed to the published version of the manuscript.

Funding: This research was funded by the Spanish Ministry of Economy and Competitiveness and European ERDF Funds (MCIU/AEI/FEDER, EU) (RTI2018-097991-B-I00 to J.L.N. and BFU2016-78232-P to A.V.C.); La Ligue Contre le Cancer, INCa, Canceropole PACA, and INSERM to J.L.I.; Miguel Servet Program from Instituto de Salud Carlos III (CPII13/00017 to OA); Fondo de Investigaciones Sanitarias from Instituto de Salud Carlos III and European Union (ERDF/ESF, "Investing in your future") (PI15/00663 and PI18/00349 to O.A.); Diputación General de Aragón (Protein Targets and Bioactive Compounds Group E45_17R to A.V.C. and Digestive Pathology Group B25_17R to O.A.); and the Centro de Investigación Biomédica en Red en Enfermedades Hepáticas y Digestivas (CIBERehd). The NMR equipment used in this work was funded by the Generalitat Valenciana and cofinanced with ERDF funds (OP ERDF of Comunitat Valenciana 2014-2020).

Acknowledgments: We thank J. K. Forwood (Charles Sturt University, Waga Waga, Autralia) for the kind gift of the $\Delta \operatorname{Imp} \alpha 3$ vector. B.R. acknowledges the kind hospitality and use of computational resources in the European Magnetic Resonance Center (CERM), Sesto Fiorentino (Florence), Italy. We thank the three anonymous reviewers for their helpful comments and suggestions.

Conflicts of Interest: The authors declare no conflict of interest. The funders had no role in the design of the study; in the collection, analyses, or interpretation of data; in the writing of the manuscript; or in the decision to publish the results.

\section{References}

1. Stewart, M. Molecular mechanism of the nuclear protein import cycle. Nat. Rev. Mol. Cell Boil. 2007, 8, 195-208. [CrossRef]

2. Bednenko, J.; Cingolari, G.; Gerace, L. Nucleo-cytoplasmic transport navigating the channel. Traffic 2003, 4, 127-135. [CrossRef] [PubMed]

3. Cingolani, G.; Bednenko, J.; Gillespie, M.T.; Gerace, L. Molecular basis for the recognition of a non-classical nuclear localization signal by importin beta. Mol. Cell 2002, 10, 1345-1353. [CrossRef] 
4. Goldfarb, D.S.; Corbett, A.H.; Mason, D.A.; Harreman, M.T.; Adam, S.A. Importin $\alpha$ : A multipurpose nuclear-transport receptor. Trends Cell Boil. 2004, 14, 505-514. [CrossRef] [PubMed]

5. Pumroy, R.A.; Cingolani, G. Diversification of importin- $\alpha$ isoforms in cellular trafficking and disease states. Biochem. J. 2015, 466, 13-28. [CrossRef]

6. Mason, D.A.; Stage, D.E.; Goldfarb, D. Evolution of the metazoan-specific importin $\alpha$ gene family. J. Mol. Evol. 2009, 68, 351-365. [CrossRef]

7. Miyamoto, Y.; Loveland, K.L.; Yoneda, Y. Nuclear importin $\alpha$ and its physiological importance. Commun. Integr. Boil. 2012, 5, 220-222. [CrossRef]

8. Smith, K.M.; Tsimbalyuk, S.; Edwards, M.R.; Cross, E.M.; Batra, J.; Da Costa, T.P.S.; Aragão, D.; Basler, C.; Forwood, J. Structural basis for importin alpha 3 specificity of $\mathrm{W}$ proteins in Hendra and Nipah viruses. Nat. Commun. 2018, 9, 3703. [CrossRef]

9. Kobe, B. Autoinhibition by an internal nuclear localization signal revealed by the crystal structure of mammalian importin $\alpha$. Nat. Struct. Biol. 1999, 6, 388-397. [CrossRef]

10. Berlow, R.B.; Dyson, H.J.; Wright, P.E. Expanding the Paradigm: Intrinsically Disordered Proteins and Allosteric Regulation. J. Mol. Boil. 2018, 430, 2309-2320. [CrossRef]

11. Xie, H.M.; Vucetic, S.; Iakoucheva, L.M.; Oldfield, C.J.; Dunker, A.K.; Uversky, V.N.; Obradovict, Z. Functional Anthology of Intrinsic Disorder. 1. Biological Processes and Functions of Proteins with Long Disordered Regions. J. Proteome Res. 2007, 6, 1882-1898. [CrossRef] [PubMed]

12. Babu, M.M.; Van Der Lee, R.; De Groot, N.S.; Gsponer, J. Intrinsically disordered proteins: Regulation and disease. Curr. Opin. Struct. Boil. 2011, 21, 432-440. [CrossRef] [PubMed]

13. Gsponer, J.; Futschik, M.E.; Teichmann, S.A.; Babu, M.M. Tight Regulation of Unstructured Proteins: From Transcript Synthesis to Protein Degradation. Science 2008, 322, 1365-1368. [CrossRef]

14. Bah, A.; Forman-Kay, J.D. Modulation of Intrinsically Disordered Protein Function by Post-translational Modifications. J. Boil. Chem. 2016, 291, 6696-6705. [CrossRef]

15. Launay, H.; Receveur-Bréchot, V.; Carrière, F.; Gontero, B. Orchestration of algal metabolism by protein disorder. Arch. Biochem. Biophys. 2019, 672, 108070. [CrossRef]

16. Mallo, G.V.; Fiedler, F.; Calvo, E.L.; Ortiz, E.M.; Vasseur, S.; Keim, V.; Morisset, J.; Iovanna, J.L. Cloning and Expression of the Rat p8 cDNA, a New Gene Activated in Pancreas during the Acute Phase of Pancreatitis, Pancreatic Development, and Regeneration, and Which Promotes Cellular Growth. J. Boil. Chem. 1997, 272, 32360-32369. [CrossRef]

17. Chowdhury, U.R.; Samant, R.S.; Fodstad, O.; Shevde, L.A. Emerging role of nuclear protein 1 (NUPR1) in cancer biology. Cancer Metastasis Rev. 2009, 28, 225-232. [CrossRef] [PubMed]

18. Goruppi, S.; Iovanna, J.L. Stress-inducible Protein p8 Is Involved in Several Physiological and Pathological Processes. J. Boil. Chem. 2009, 285, 1577-1581. [CrossRef]

19. Cano, C.; Hamidi, T.; Sandi, M.J.; Iovanna, J.L. Nupr1: The Swiss-knife of cancer. J. Cell. Physiol. 2010, 226, 1439-1443. [CrossRef] [PubMed]

20. Malicet, C.; Giroux, V.; Vasseur, S.; Dagorn, J.C.; Neira, J.L.; Iovanna, J.L. Regulation of apoptosis by the p8/prothymosin alpha complex. Proc. Natl. Acad. Sci. USA 2006, 103, 2671-2676. [CrossRef]

21. Encinar, J.A.; Mallo, G.V.; Mizyrycki, C.; Giono, L.E.; González-Ros, J.M.; Rico, M.; Cánepa, E.T.; Moreno, S.; Neira, J.L.; Iovanna, J.L. Human $\mathrm{p} 8$ is a HMG-I/Y-like protein with DNA binding activity enhanced by phosphorylation. J. Boil. Chem. 2000, 276, 2742-2751. [CrossRef]

22. Aguado-Llera, D.; Hamidi, T.; Doménech, R.; Pantoja-Uceda, D.; Gironella, M.; Santoro, J.; Velázquez-Campoy, A.; Neira, J.L.; Iovanna, J.L. Deciphering the binding between Nupr1 and MSL1 and Their DNA-Repairing Activity. PLoS ONE 2013, 8, e78101. [CrossRef] [PubMed]

23. Neira, J.L.; Bintz, J.; Arruebo, M.; Rizzuti, B.; Bonacci, T.; Vega, S.; Lanas, A.; Velázquez-Campoy, A.; Iovanna, J.L.; Abián, O. Identification of a Drug Targeting an intrinsically disordered protein involved in pancreatic adenocarcinoma. Sci. Rep. 2017, 7, 39732. [CrossRef] [PubMed]

24. Santofimia-Castaño, P.; Rizzuti, B.; Pey, A.L.; Soubeyran, P.; Vidal, M.; Urrutia, R.; Iovanna, J.L.; Neira, J.L. Intrinsically disordered chromatin protein NUPR1 binds to the C-terminal region of Polycomb RING1B. Proc. Natl. Acad. Sci. USA 2017, 114, E6332-E6341. [CrossRef] [PubMed]

25. Valacco, M.P.; Varone, C.L.; Malicet, C.; Cánepa, E.T.; Iovanna, J.L.; Moreno, S. Cell growth-dependent subcellular localization of p8. J. Cell. Biochem. 2006, 97, 1066-1079. [CrossRef] 
26. Jäkel, S.; Mingot, J.-M.; Schwarzmaier, P.; Hartmann, E.; Görlich, D. Importins fulfil a dual function as nuclear import receptors and cytoplasmic chaperones for exposed basic domains. EMBO J. 2002, 21, 377-386. [CrossRef]

27. Marvaldi, L.; Panayotis, N.; Alber, S.; Dagan, S.Y.; Okladnikov, N.; Koppel, I.; Di Pizio, A.; Song, D.-A.; Tzur, Y.; Terenzio, M.; et al. Importin $\alpha 3$ regulates chronic pain pathways in peripheral sensory neurons. Science 2020, 369, 842-846. [CrossRef]

28. Gill, S.C.; Von Hippel, P.H. Calculation of protein extinction coefficients from amino acid sequence data. Anal. Biochem. 1989, 182, 319-326. [CrossRef]

29. Danielsson, J.; Jarvet, J.; Damberg, P.; Gräslund, A. Translational diffusion measured by PFG-NMR on full length and fragments of the Alzheimer $A \beta(1-40)$ peptide. Determination of hydrodynamic radii of random coil peptides of varying length. Magn. Reson. Chem. 2002, 40, S89-S97. [CrossRef]

30. Neira, J.L.; Hornos, F.; Bacarizo, J.; Camara-Artigas, A.; Gómez, J. The monomeric species of the regulatory domain of Tyrosine Hydroxylase has a low conformational stability. Biochemistry 2016, 55, 3418-3431. [CrossRef]

31. Benjwal, S.; Verma, S.; Röhm, K.; Gursky, O. Monitoring protein aggregation during thermal unfolding in circular dichroism experiments. Protein Sci. 2006, 15, 635-639. [CrossRef] [PubMed]

32. Santofimia-Castaño, P.; Xia, Y.; Lan, W.; Zhou, Z.; Huang, C.; Peng, L.; Soubeyran, P.; Velázquez-Campoy, A.; Abian, O.; Rizzuti, B.; et al. Ligand-based design identifies a potent NUPR1 inhibitor exerting anticancer activity via necroptosis. J. Clin. Investig. 2019, 129, 2500-2513. [CrossRef] [PubMed]

33. Cavanagh, J.; Fairbrother, W.J.; Palmer, A.G.; Skelton, N.J. Protein NMR Spectroscopy: Principles and Practice; Academic Press: New York, NY, USA, 1996.

34. Wilkins, D.K.; Grimshaw, S.B.; Receveur, V.; Dobson, C.M.; Jones, J.A.; Smith, L.J. Hydrodynamic radii of native and denatured proteins measured by pulse field gradient NMR techniques. Biochemistry 1999, 38, 16424-16431. [CrossRef] [PubMed]

35. Marion, D.; Wüthrich, K. Application of phase sensitive two-dimensional correlated spectroscopy (COSY) for measurements of $1 \mathrm{H}-1 \mathrm{H}$ spin-spin coupling constants in proteins. Biochem. Biophys. Res. Commun. 1983, 113, 967-974. [CrossRef]

36. Bax, A.; Davis, D.G. MLEV-17-based two-dimensional homonuclear magnetization transfer spectroscopy. J. Magn. Reson. 1985, 65, 355-360. [CrossRef]

37. Kumar, A.; Ernst, R.; Wüthrich, K. A two-dimensional nuclear Overhauser enhancement (2D NOE) experiment for the elucidation of complete proton-proton cross-relaxation networks in biological macromolecules. Biochem. Biophys. Res. Commun. 1980, 95, 1-6. [CrossRef]

38. Cavanagh, J.; Rance, M. Suppression of cross-relaxation effects in TOCSY spectra via a modified DIPSI-2 mixing sequence. J. Magn. Reson. 1992, 96, 670-678. [CrossRef]

39. Piotto, M.; Saudek, V.; Sklenář, V. Gradient-tailored excitation for single-quantum NMR spectroscopy of aqueous solutions. J. Biomol. NMR 1992, 2, 661-665. [CrossRef]

40. Wüthrich, K. NMR of Proteins and Nucleic Acids; John Wiley and Sons: New York, NY, USA, 1986.

41. Kjaergaard, M.; Brander, S.; Poulsen, F.M. Random coil chemical shift for intrinsically disordered proteins: Effects of temperature and pH. J. Biomol. NMR 2011, 49, 139-149. [CrossRef]

42. Kjaergaard, M.; Poulsen, F.M. Sequence correction of random coil chemical shifts: Correlation between neighbor correction factors and changes in the Ramachandran distribution. J. Biomol. NMR 2011, 50, 157-165. [CrossRef]

43. Bienkiewicz, E.A.; Lumb, K.J. Random-coil chemical shifts of phosphorylated amino acids. J. Biomol. NMR 1999, 15, 203-206. [CrossRef] [PubMed]

44. Hendus-Altenburger, R.; Fernandes, C.B.; Bugge, K.; Kunze, M.B.A.; Boomsma, W.; Kragelund, B.B. Random coil chemical shifts for serine, threonine and tyrosine phosphorylation over a broad pH range. J. Biomol. NMR 2019, 73, 713-725. [CrossRef] [PubMed]

45. Trott, O.; Olson, A.J. AutoDock Vina: Improving the speed and accuracy of docking with a new scoring function, efficient optimization, and multithreading. J. Comput. Chem. 2009, 31, 455-461. [CrossRef] [PubMed]

46. Nakada, R.; Matsuura, Y. Crystal structure of importin- $\alpha$ bound to the nuclear localization signal of Epstein-Barr virus EBNA-LP protein. Protein Sci. 2017, 26, 1231-1235. [CrossRef] [PubMed] 
47. Forli, S.; Huey, R.; Pique, M.E.; Sanner, M.F.; Goodsell, D.S.; Olson, A.J. Computational protein-ligand docking and virtual drug screening with the AutoDock suite. Nat. Protoc. 2016, 11, 905-919. [CrossRef]

48. Grande, F.; Rizzuti, B.; Occhiuzzi, M.A.; Ioele, G.; Casacchia, T.; Gelmini, F.; Guzzi, R.; Garofalo, A.; Statti, G. Identification by molecular docking of homoisoflavones from Leopoldia comosa as ligands of estrogen receptors. Molecules 2018, 23, 894. [CrossRef]

49. Grimsley, G.R.; Huyghues-Despointes, B.M.; Pace, C.N.; Scholtz, J.M. Measuring the Conformational Stability of a Protein by NMR. Cold Spring Harb. Protoc. 2006, 2006, 253-259. [CrossRef]

50. Lan, W.; Santofimia-Castaño, P.; Swayden, M.; Xia, Y.; Zhou, Z.; Audebert, S.; Camoin, L.; Huang, C.; Peng, L.; Jiménez-Alesanco, A.; et al. ZZW-115-dependent inhibition of NUPR1 nuclear translocation sensitizes cancer cells to genotoxic agents. JCI Insight 2020, 138117. [CrossRef]

51. Neira, J.L.; López, M.B.; Sevilla, P.; Rizzuti, B.; Camara-Artigas, A.; Vidal, M.; Iovanna, J.L. The chromatin nuclear protein NUPR1L is intrinsically disordered and binds to the same proteins as its paralogue. Biochem. J. 2018, 475, 2271-2291. [CrossRef]

52. Santofimia-Castaño, P.; Rizzuti, B.; Abian, O.; Velázquez-Campoy, A.; Iovanna, J.L.; Neira, J.L. Amphipathic helical peptides hamper protein-protein interactions of the intrinsically disordered chromatin nuclear protein 1 (NUPR1). Biochim. Biophys. Acta Gen. Subj. 2018, 1862, 1283-1295. [CrossRef]

53. Miyatake, H.; Sanjoh, A.; Unzai, S.; Matsuda, G.; Tatsumi, Y.; Miyamoto, Y.; Dohmae, N.; Aida, Y. Crystal structure of human Importin- $\alpha 1$ (Rch1), revealing a potential autoinhibition mode involving homodimerization. PLoS ONE 2015, 10, e115995. [CrossRef] [PubMed]

54. Sankhala, R.S.; Lokareddy, R.K.; Begum, S.; Pumroy, R.A.; Gillilan, R.E.; Cingolani, G. Three-dimensional context rather than NLS amino acid sequence determines importin $\alpha$ subtype specificity for RCC1. Nat. Commun. 2017, 8, 979. [CrossRef] [PubMed]

55. Pumroy, R.A.; Ke, S.; Hart, D.J.; Zacharie, U.; Cingolani, G. Molecular determinants for nuclear import if influenza A PB2 by importin alpha isoforms 3 and 7. Structure 2015, 23, 374-384. [CrossRef] [PubMed]

56. Junod, S.L.; Kelich, J.M.; Ma, J.; Yang, W. Nucleocytoplasmic transport of intrinsically disordered proteins studied by high-speed super-resolution microscopy. Protein Sci. 2020, 29, 1459-1472. [CrossRef]

57. Neira, J.L.; Correa, J.; Rizzuti, B.; Santofimia-Castaño, P.; Abián, O.; Velázquez-Campoy, A.; Fernandez-Megia, E.; Iovanna, J.L. Dendrimers as competitors of protein-protein interactions of the intrinsically disordered nuclear chromatin protein NUPR1. Biomacromolecules 2019, 20, 2567-2576. [CrossRef]

58. Yadahalli, S.; Neira, J.L.; Johnson, C.M.; Tan, Y.S.; Rowling, P.J.E.; Chattopadhyay, A.; Verma, C.; Itzhaki, L.S. Kinetic and thermodynamic effects of phosphorylation on p53 binding to MDM2. Sci. Rep. 2019, 9, 693. [CrossRef]

59. Bah, A.; Vernon, R.M.; Siddiqui, Z.; Krzeminski, M.; Muhandiram, R.; Zhao, C.W.; Sonenberg, N.; Kay, L.E.; Forman-Kay, J.D. Folding of an intrinsically disordered protein by phosphorylation as a regulatory switch. Nature 2014, 519, 106-109. [CrossRef]

60. Gandhi, N.S.; Landrieu, I.; Byrne, C.; Kukić, P.; Amniai, L.; Cantrelle, F.-X.; Wieruszeski, J.-M.; Mancera, R.L.; Jacquot, Y.; Lippens, G. A Phosphorylation-induced turn defines the Alzheimer's disease AT8 antibody epitope on the Tau protein. Angew. Chem. Int. Ed. 2015, 54, 6819-6823. [CrossRef]

61. Beck, D.A.C.; Alonso, D.O.V.; Inoyama, D.; Daggett, V. The intrinsic conformational propensities of the 20 naturally occurring amino acids and reflection of these propensities in proteins. Proc. Natl. Acad. Sci. USA 2008, 105, 12259-12264. [CrossRef]

62. Muñoz, V.; Serrano, L. Intrinsic secondary structure propensities of the amino acids, using statistical $\varphi-\psi$ matrices: Comparison with experimental scales. Proteins: Struct. Funct. Bioinform. 1994, 20, 301-311. [CrossRef]

63. Gibbs, E.B.; Lu, F.; Portz, B.; Fisher, M.J.; Medellin, B.P.; Laremore, T.N.; Zhang, Y.S.; Gimour, D.S.; Showalter, S.A. Phosphorylation induces sequence-specific conformational switches in the RNA polymerase II C-terminal domain. Nat. Commun. 2017, 8, 15233. [CrossRef] [PubMed]

64. Xiang, S.; Gapsys, V.; Kim, H.-Y.; Bessonov, S.; Hsiao, H.-H.; Möhlmann, S.; Klaukien, V.; Ficner, R.; Becker, S.; Urlaub, H.; et al. Phosphorylation drives a dynamic switch in Serine/Arginine-rich proteins. Structure 2013, 21, 2162-2174. [CrossRef] [PubMed]

65. Turner, A.L.; Watson, M.; Wilkins, O.G.; Cato, L.; Travers, A.; Thomas, J.O.; Stott, K. Highly disordered histone H1-DNA model complexes and their condensates. Proc. Natl. Acad. Sci. USA 2018, 115, 11964-11969. [CrossRef] [PubMed] 
66. Banavali, N.K.; Roux, B. Anatomy of a structural pathway for activation of the catalytic domain of Src kinase Hck. Proteins: Struct. Funct. Bioinform. 2007, 67, 1096-1112. [CrossRef]

67. Espinoza-Fonseca, L.M.; Kast, D.; Thomas, D.D. Molecular dynamics simulations reveal a disorder-to-order transition on phosphorylation of smooth muscle myosin. Biophys. J. 2007, 93, 2083-2090. [CrossRef]

68. Hendus-Altenburger, R.; Lambrughi, M.; Terkelsen, T.; Pedersen, S.F.; Papaleo, E.; Lindorff-Larsen, K.; Kragelund, B.B. A phosphorylation-motif for tuneable helix stabilisation in intrinsically disordered proteins-Lessons from the sodium proton exchanger 1 (NHE1). Cell. Signal. 2017, 37, 40-51. [CrossRef]

69. Chu, I.M.; Hengst, L.; Slingerland, J.M. The Cdk inhibitor p27 in human cancer: Prognostic potential and relevance to anticancer therapy. Nat. Rev. Cancer 2008, 8, 253-267. [CrossRef]

70. He, Y.; Chen, Y.; Mooney, S.M.; Rajagopalan, K.; Bhargava, A.; Sacho, E.; Weninger, K.; Bryan, P.N.; Kulkarni, P.; Orban, J. Phosphorylation-induced conformational ensemble switching in an intrinsically disordered cancer/testis antigen*. J. Boil. Chem. 2015, 290, 25090-25102. [CrossRef]

71. Zimmermann, M.T.; Williams, M.M.; Klee, E.W.; Lomberk, G.L.; Urrutia, R.A. Modeling post-translational modifications and cancer-associated mutations that impact the heterochromatin protein $1 \alpha$-importin $\alpha$ heterodimers. Proteins: Struct. Funct. Bioinform. 2019, 87, 904-916. [CrossRef]

(C) 2020 by the authors. Licensee MDPI, Basel, Switzerland. This article is an open access article distributed under the terms and conditions of the Creative Commons Attribution (CC BY) license (http://creativecommons.org/licenses/by/4.0/). 